\title{
Fabrication of Fe-2.1 wt.\% Si Alloy Sheets with Dominant Goss Texture Through Thickness
}

\author{
Ning Shan ${ }^{a}$, JinLong Liu ${ }^{a} *$, YuHui Sha ${ }^{a}$, Fang Zhang $^{a}$, Liang Zuo ${ }^{a}$ \\ ${ }^{a}$ Key Laboratory for Anisotropy and Texture of Materials (Ministry of Education), School of Materials \\ Science and Engineering, Northeastern University, Shenyang 110819, China
}

Received: November 25, 2018; Revised: May 13, 2019; Accepted: May 19, 2019

\begin{abstract}
Macro- and micro-texture of Fe-2.1 wt.\% Si alloy sheets were investigated and analyzed by X-ray diffraction and electron backscattered diffraction techniques. A Goss $(\{110\}<001>)$ component accompanied by extremely weak $\gamma(<111>/ / \mathrm{ND}$, normal direction) fiber is successfully formed through the sheet thickness after primary recrystallization and considerable grain growth. Goss grains mainly nucleate at shear bands in various deformed matrices with orientations spreading from $<112>/$ ND to $<332>/$ /ND fibers. The formation of dominant Goss recrystallization texture through the thickness can be attributed to the suppression of the nucleation at grain boundaries of $\gamma$ deformed matrices and the promotion of the nucleation at shear bands in various deformed matrices, based on optimization of the initial texture and microstructure and the applied processing parameters.
\end{abstract}

Keywords: Electrical steels, Goss texture, rolling, recrystallization, EBSD.

\section{Introduction}

Fe-2.1 wt.\% Si alloys are widely used as core materials in generators and motors due to excellent magnetic properties and high-cost performance. The magnetic properties of Fe-2.1 wt.\% Si alloys are extremely sensitive to the recrystallization texture. Goss $(\{110\}<001>)$ is a beneficial recrystallization texture component, because Goss has one easy magnetization $<001>$ direction in the rolling plane, while $\gamma$ fiber $(<111>/ /$ $\mathrm{ND}$, normal direction) is detrimental due to the lack of $<001>$ direction in the rolling plane. However, $\gamma$ recrystallization texture is usually preferentially developed after cold rolling and final annealing in the industrial production ${ }^{1-4}$.

It is known that $\gamma$ grains mainly nucleate at the grain boundaries of $\gamma$ deformed grains ${ }^{5-8}$, and some investigations ${ }^{2-5,9-14}$ have revealed some efficient ways to decrease recrystallization $\gamma$ fiber. Lee et al. ${ }^{2-4}$ reported that increasing the initial grain size can weaken recrystallization $\gamma$ fiber by reducing the volume of grain boundaries in Fe-2 wt.\% Si alloys. Paolinelli et al. ${ }^{9}$ observed that the decrease of $\alpha$ fiber of hot band contributes to weakening recrystallization $\gamma$ fiber in Fe-3.2 wt.\% Si alloy. Decreasing hot rolling $\gamma$ texture is also a useful way to weaken the recrystallization $\gamma$ texture based on the investigation of Eloot et al. ${ }^{5}$. In addition, twostage cold rolling ${ }^{9,10}$ and temper rolling ${ }^{14}$ are proved to be effective to suppress $\gamma$ recrystallization texture by weakening the strain-stored energy of grain boundaries and inducing other oriented grains of low stored energy to consume small $\gamma$ recrystallized grains, respectively. However, it is difficult to completely eliminate $\gamma$ texture through all these methods.

Goss grains mainly nucleate at the shear bands in $\gamma$ deformed grains ${ }^{8,15-18}$, especially $\{111\}<112>$ deformed matrices, so promoting the formation of shear bands is an important way to control Goss texture. It is generally believed that hot rolling Goss texture is beneficial to the formation of Goss recrystallization texture. Hot rolling Goss texture can rotate to $\gamma$ fiber during cold rolling, and the research has shown that shear bands can be well developed in $\{111\}<112>$ deformed matrices originating from Goss single crystals under $77 \%$ reductions ${ }^{15}$. But the hot rolling Goss texture has remarkable gradient characteristic. Goss texture usually forms at the surface and subsurface layers for bearing strong shear strain (SSS) during hot rolling, while very strong $\alpha$ fiber usually appears at the center layer due to strong plane strain (SPS) ${ }^{19-21}$. And the texture and microstructure gradient in the hot band can result in the inhomogeneity through the thickness in recrystallization texture due to the inherited effect of texture. Therefore, it is needed to optimize the microstructure and texture characteristics in the whole fabrication process of $\mathrm{Fe}-2.1 \mathrm{wt} . \% \mathrm{Si}$ alloy sheets in the industrial production for controlling Goss recrystallization texture through the thickness, which is, however, still far from optimization ${ }^{1-4}$.

In the present work, Fe-2.1 wt.\% Si alloy sheets with dominant Goss texture through the thickness were produced by designing the hot rolling microstructure and texture and optimizing the subsequent fabricating parameters. Microstructure and texture evolution were analyzed to explore the optimizing mechanism of Goss texture.

\section{Materials and Methods}

Fe-2.1 wt.\% Si alloy ingots were prepared by vacuum induction melting. The chemical composition (in wt.\%) of the investigated alloy is shown in Table 1. The ingots were forged to $80 \mathrm{~mm}$ and then hot rolled to $3.5 \mathrm{~mm}$ in thickness at a temperature ranging from 1200 to $950{ }^{\circ} \mathrm{C}$. 
The microstructure and texture of hot bands have been reported in the previous paper ${ }^{22}$. Afterwards, hot bands were subjected to normalizing annealing at $1030{ }^{\circ} \mathrm{C}$ for 10 min and further cold rolled at room temperature under $70 \%$ reduction. Finally, some cold rolled sheets were annealed at $850^{\circ} \mathrm{C}$ for $10 \mathrm{~min}$ in flowing $\mathrm{Ar}$ atmosphere for the study of recrystallization texture and microstructure, and $650{ }^{\circ} \mathrm{C}$ for 2,5 , and $10 \mathrm{~min}$ for observation of microstructure evolution during recrystallization process. Other cold rolled sheets were annealed at $640{ }^{\circ} \mathrm{C}$ for $2 \mathrm{~min}$ and $750{ }^{\circ} \mathrm{C}$ for $3 \mathrm{~min}$ in order to obtain $10 \%$ and just completely recrystallized fractions for analysis of micro-texture.

The macro-texture of the specimens was studied by X-ray diffraction (XRD) technique through the sheet thickness layer. Here, the thickness layer is defined as the parameter $S=2 a / d$, where $a$ represents the distance away from the center layer and $d$ is the whole sheet thickness. The orientation distribution function (ODF) was calculated from the three incomplete pole figures of $\{110\},\{200\}$, and $\{112\}$. Volume fractions of texture components based on XRD data were calculated by the ATEX software ${ }^{23}$. The micro-texture of the specimens was analyzed using orientation imaging microscopy (OIM) by electron backscattered diffraction (EBSD) technique. Texture components in XRD and EBSD analyses are defined within $15^{\circ}$ around the ideal orientations in Euler space. Optical microscopy and EBSD were applied in the longitudinal section as defined by the rolling direction and normal direction. The statistic of grain size was determined by a mean linear intercept method along the rolling direction.

\section{Results and Discussion}

\subsection{Microstructure and texture of recrystallization}

Figure 1 gives the microstructure and texture of normalized hot bands. The microstructure shows a certain extent of heterogeneous distribution with equiaxed grains. Average grain size continuously increases from 80 to 136 $\mu \mathrm{m}$ with the value of $S$ decreasing. The texture of normalized hot bands is similar to the hot rolling texture, and exhibits some thickness gradient that is inherited from the hot rolling texture. Goss and Cube components still dominate the textures at the $S=0.5$ and $S=0$ layers in normalized hot bands, respectively. But the orientation intensity obviously reduces after normalizing. Moreover, the volume fractions of $\{001\}<110>$ and $\{111\}<112>$ are extremely low through the thickness layer, especially $\{111\}<112>$. It should be noted that the textures of normalized hot bands in this work are obviously different from those of traditional normalized hot bands ${ }^{9,19}$, in which stronger Goss texture at the $S=0.5$ layer and more intense $\alpha$ texture and weaker cube texture at the $S=0$ layer are usually formed.

Figure 2 presents the microstructure evolution of cold rolled Fe-2.1 wt.\% $\mathrm{Si}$ alloy sheets during the isothermal annealing process. In-grain shear bands with an inclination angle of $20-35^{\circ}$ to the RD are extensively distributed through the sheet thickness after cold rolling. Recrystallized grains non-uniformly nucleate at shear bands and grain boundaries after annealing at $650{ }^{\circ} \mathrm{C}$ for $2 \mathrm{~min}$ (Figure 2(b)). Additionally, it should be noted that there exist abundant shear bands and nucleation at shear bands at the $S=0$ layer. After final annealing at $850{ }^{\circ} \mathrm{C}$ for $10 \mathrm{~min}$, complete recrystallization and considerable grain growth occur in cold rolled sheets. The microstructure is homogeneously distributed with equiaxed grains through the sheet thickness and the average grain size slightly increases from 47 to $53 \mu \mathrm{m}$ with the value of $S$ decreasing. It is worthy to note that strong Goss and relatively weak cube surprisingly dominate the recrystallization texture through the sheet thickness. And Goss gets the maximal orientation density at the $S=0.5$ layer and cube strengthens with the value of $S$ decreasing. In contrast, $\{111\}<112>$ and $\{111\}<110>$ components are extremely weak.

Table 1. Chemical composition (in wt.\%) of the investigated alloy.

\begin{tabular}{ccccccccc}
\hline $\mathrm{C}$ & $\mathrm{Si}$ & $\mathrm{Mn}$ & $\mathrm{Al}$ & $\mathrm{S}$ & $\mathrm{P}$ & \\
\hline 0.01 & 2.1 & 0.2 & 0.002 & 0.004 & Fe & 0.017 & Bal. \\
\hline
\end{tabular}

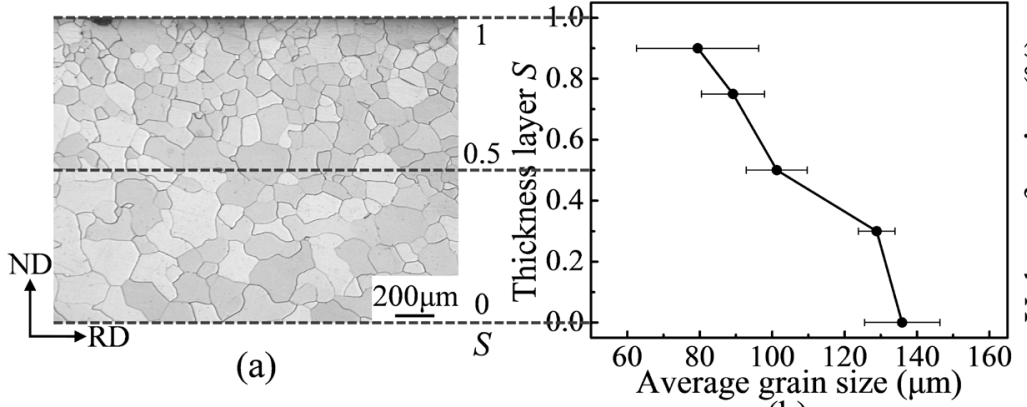

(b)

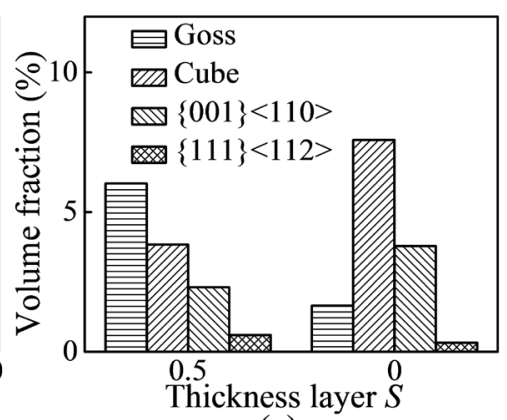

(c)

Figure 1. (a) Microstructure, (b) average grain size through the thickness, and (c) volume fraction of main texture components in Fe-2.1 wt.\% Si normalized hot bands. 

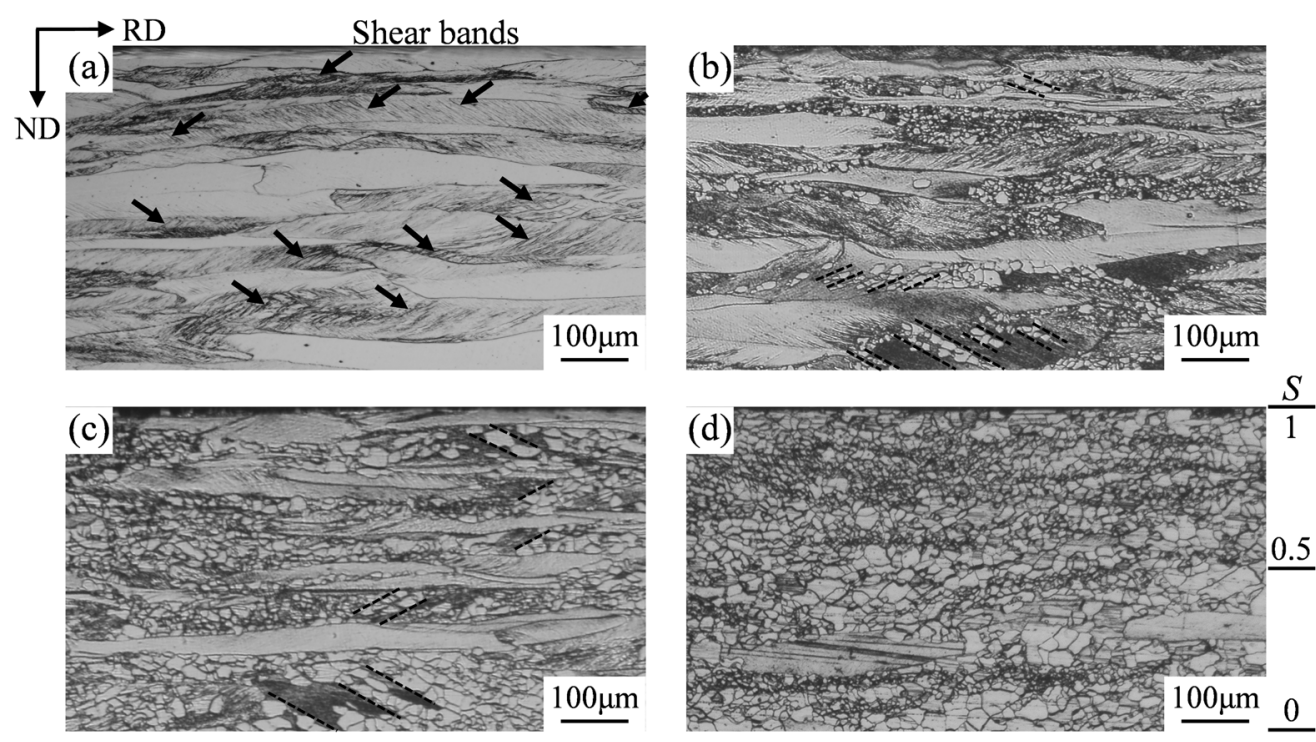

Figure 2. Optical microstructures of Fe-2.1 wt.\% Si sheets after (a) cold rolling, and annealing at $650{ }^{\circ} \mathrm{C}$ for (b) $2 \mathrm{~min}$, (c) $5 \mathrm{~min}$, and (d) $10 \mathrm{~min}$.

\subsection{Nucleation and growth of Goss grains}

In order to further investigate the development of Goss recrystallization texture through the thickness, the $10 \%$ recrystallized sheets were analyzed by EBSD technique. Figure 4 gives nucleation at shear bands within several deformed matrices. It can be apparently seen that new nuclei are mainly of Goss orientation and can nucleate at shear bands in the $\{223\}<334>,\{111\}<123>,\{332\}<243>$, $\{332\}<110>$, and $\{112\}<021>$ deformed matrices. The five deformed matrices are located on both sides of $\gamma$ fiber on the $\varphi_{2}=45^{\circ}$ section of ODFs, as shown in Figure 4(f). Moreover, numerous studies ${ }^{8,15-18}$ showed that Goss grains can nucleate at shear bands in $\{111\}<112>,\{111\}<110>$, and $\{112\}<110>$ deformed matrices. Therefore, the nucleation environment of Goss grains is closely related to shear bands in deformed matrices with orientations spreading from $<112>/$ /ND to $<332>/ / \mathrm{ND}$ fibers with the deviation angle up to $20^{\circ}$ away from accurate $\gamma$ fiber, as shown in the shadow area in Figure 4(f).

Figure 5 presents micro-texture of just completely recrystallized Fe-2.1 wt.\% Si alloy sheets. Goss dominates the texture at various layer intervals and has the largest area fraction at layers of $S=0.3-0.6$. It is interesting to note that the just complete recrystallization texture is similar to the texture after considerable grain growth (Figure 3). Moreover, Goss grains have both number and size advantage in the range of grain size above $20 \mu \mathrm{m}$, which is much favorable for the preferred development of Goss texture when the grains with various orientations compete with each other in the process of growth. This phenomenon is different from the general understanding that Goss grains have no size advantage during primary recrystallization ${ }^{8,13,18,24}$.

\subsection{Formation mechanism of dominant Goss recrystallization texture through the thickness}

Then an interesting question is submitted, why does the Goss dominate the recrystallization texture at various layers of Fe-2.1 wt.\% Si sheets? It is well established that Goss and $\gamma$ grains mainly nucleate at shear bands ${ }^{8,15-18}$ and grain boundary regions $^{5-8}$ in $\gamma$ deformed grains, respectively. Therefore, the competitive relationship of preferred nucleation at shear bands or grain boundaries in the early stage of recrystallization is crucial for the control of recrystallization texture.

It is confirmed that Goss grains mainly nucleate at the shear bands in $\gamma$ and near- $\gamma$ deformed matrices as shown in Figure 4 . Thus the widely distributed $\gamma$ and near- $\gamma$ deformed grains with in-grain shear bands are the prerequisites for the formation of Goss texture. A shear band is a form of plastic instability in rolling process ${ }^{25}$, and the formation of shear band closely depends on many factors including microstructure, texture and deformation behavior.

On the one hand, the onset of shear bands is highly sensitive to the initial grain orientation and the strain. Research results ${ }^{15,16}$ showed that shear bands can be well developed in the $\{111\}<112>$ deformed matrices originating from the $\{111\}<112>$ single crystals under $28 \%$ reduction, while the shear bands are formed in the $\{111\}<112>$ deformed matrices originating from the Goss single crystals under $77 \%$ reduction. Moreover, if there are a large number of $\alpha$ grains in the initial microstructure, these $\alpha$ grains are difficult to transform into $\gamma$ deformed grains with shear bands under various deformation conditions ${ }^{26}$. Therefore, to form $\gamma$ deformed grains with shear bands in cold rolled sheets of Fe-2.1 wt.\% Si alloy, the $\gamma$ and Goss texture in hot bands 


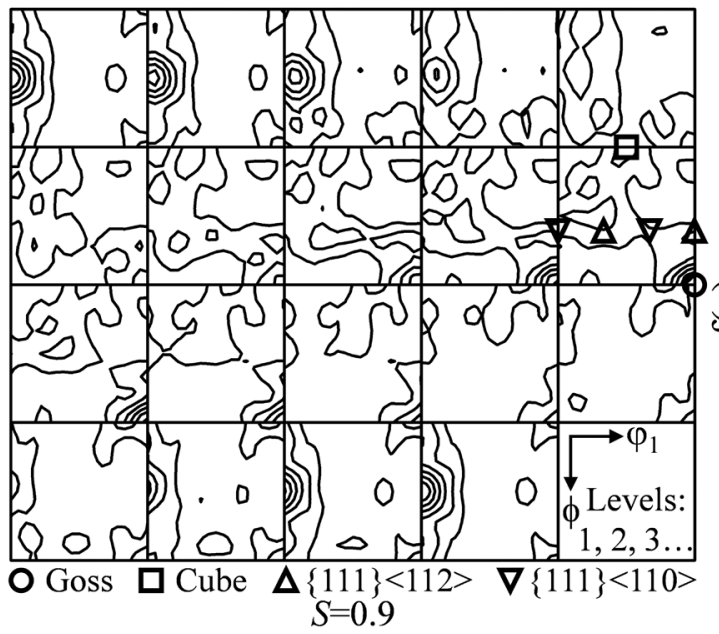

(a)

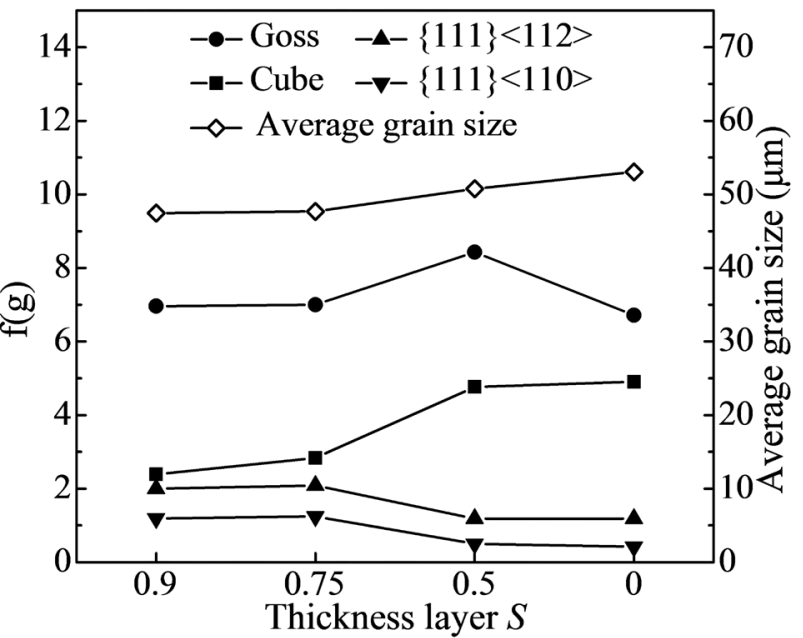

(b)

Figure 3. (a) Constant $\varphi_{2}$ sections of ODFs at the $S=0.9$ layer and (b) orientation densities of main texture components and average grain size at different thickness layers in Fe-2.1 wt.\% Si sheets after annealing at $850^{\circ} \mathrm{C}$ for $10 \mathrm{~min}$.

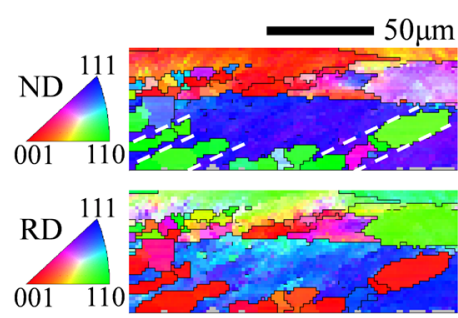

(a) $\{223\}<334>$

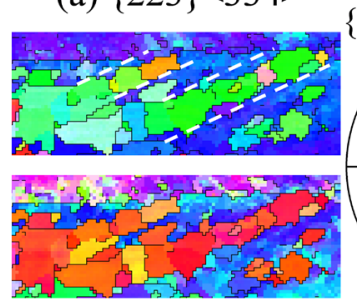

(c) $\{332\}<243>$
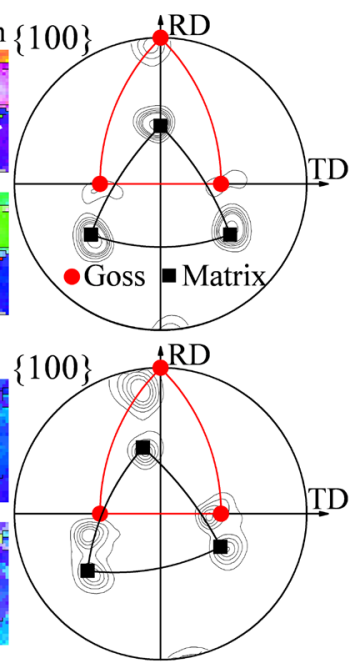

(d) $\{332\}<110>$

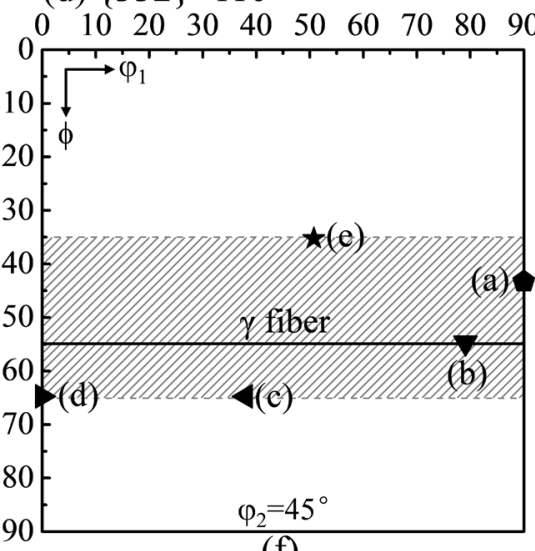

(f)

Figure 4. Orientation image maps and corresponding $\{100\}$ pole figures of recrystallized grains and correspondingly surrounded deformed matrices in $10 \%$ recrystallized Fe-2.1 wt. $\%$ Si sheets: (a) $\{223\}<334>$ matrix; (b) $\{111\}<123>$ matrix; (c) $\{332\}<243>$ matrix; (d) $\{332\}<110>$ matrix; (e) $\{112\}<021>$ matrix; (f) the crystal orientations of (a)-(e) matrices marked in the $\varphi_{2}=45^{\circ}$ section of ODFs 


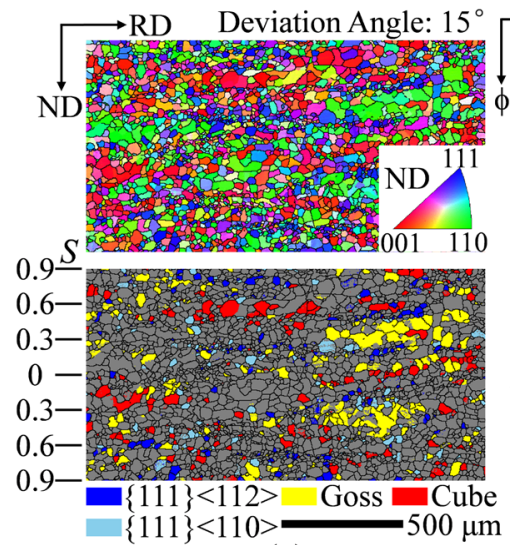

(a)

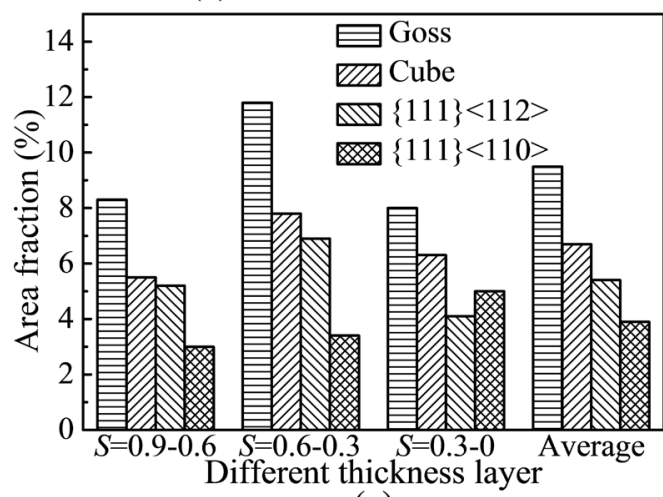

(c)

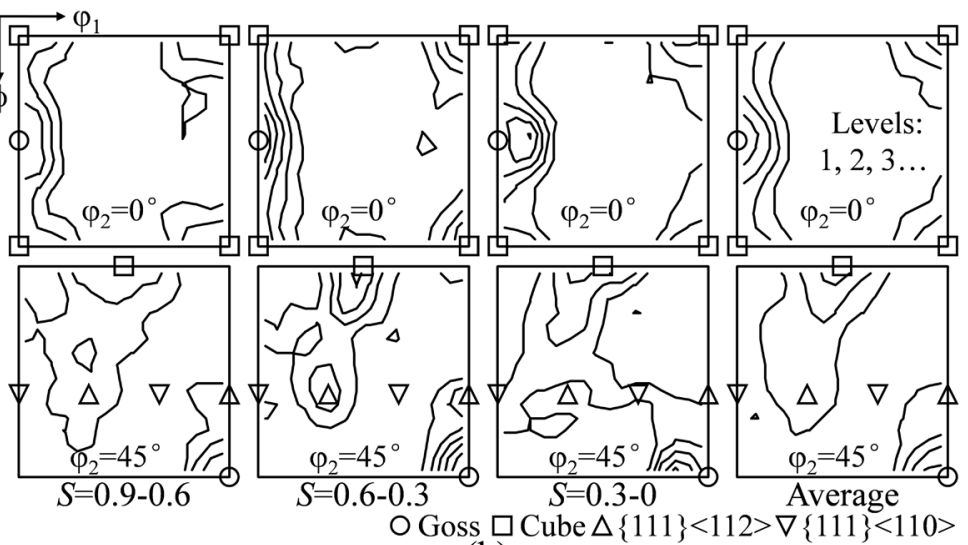

(b)

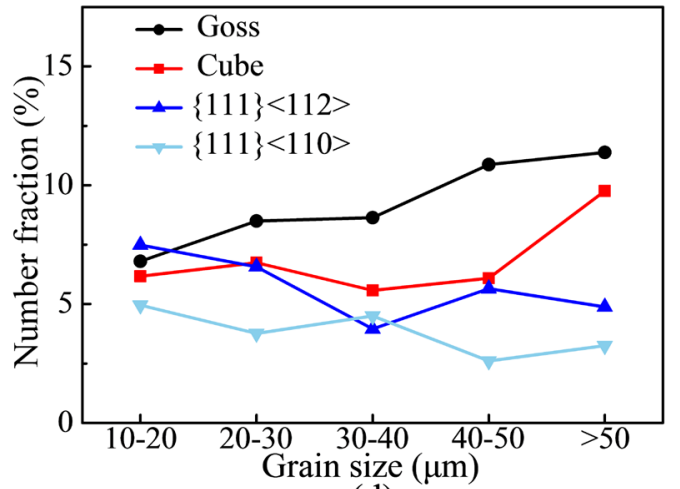

(d)

Figure 5. Micro-texture of just completely recrystallized Fe-2.1 wt.\% Si sheets after annealing at $750{ }^{\circ} \mathrm{C}$ for 3 min: (a) Orientation image maps; (b) constant $\varphi_{2}=0^{\circ}$ and $45^{\circ}$ sections of ODFs and (c) area fractions of main texture components within different thickness layers; and (d) number fraction distribution of main texture components in different size ranges.

is beneficial under the special cold rolling reductions, and the $\alpha$ texture in hot bands is unfavorable. Mishra et al. ${ }^{19-21}$ investigated the development of the Goss texture in Fe-3 wt.\% Si alloys and the results showed that it is usually more difficult to form shear bands at the center layer of cold rolled sheets than in the surface and subsurface layer, because the center layer of hot band contains much stronger $\alpha$ texture and weaker Goss texture than the surface and subsurface layer.

On the other hand, the initial grain size is another important factor, and it is much easier to form shear bands after deformation in the sheets with initial coarse grains than fine grains $\mathrm{s}^{2-4,9-13}$. So the relatively large initial grain size above $80 \mu \mathrm{m}$ through the normalized hot band thickness is very favorable for the formation of shear bands. Moreover, the initial grain size increasing from $80 \mu \mathrm{m}$ at the surface layer to the $136 \mu \mathrm{m}$ at the center layer (Figure 1(b)), is extremely beneficial to the onset of the localized shear at the center layer. In addition, $\alpha$ texture is extremely weak at the center layer of normalized bands, which further reduces the difficulty of the formation of the shear band at this layer according to the discussion in the previous paragraph. Thus abundant shear bands occur at the layers near the center of sheets, as observed in Figures 6(a) and 2(a-c).

Figures 6(b) and (c) further give orientation image maps marked in Figure 6(a) with Regions I and II and corresponding $\{100\}$ pole figures of recrystallized grains and correspondingly surrounded deformed matrices. Recrystallized grains are mainly composed of Goss grains nucleated at shear bands in $\{445\}<558>$ and $\{111\}<235>$ deformed matrices. The $\{445\}<558>$ and $\{111\}<235>$ orientations are also located in the shadow area in Figure 4(f).

Consequently, Goss recrystallized grains extensively nucleate at shear bands in $\gamma$ and near- $\gamma$ deformed grains at various layers of annealing sheets at an early stage of recrystallization as shown in figures 4 and 6 . And dominant Goss texture through the thickness (Figure 5) is formed by virtue of both the extensive nucleation at shear bands and relatively inferior nucleation at grain boundaries (Figure 6(a)) during recrystallization. After complete recrystallization, Goss texture continues to develop during the stage of grain growth derived from the advantages of both grain size and number, which further promotes the formation of Goss texture through the thickness after final annealing. 


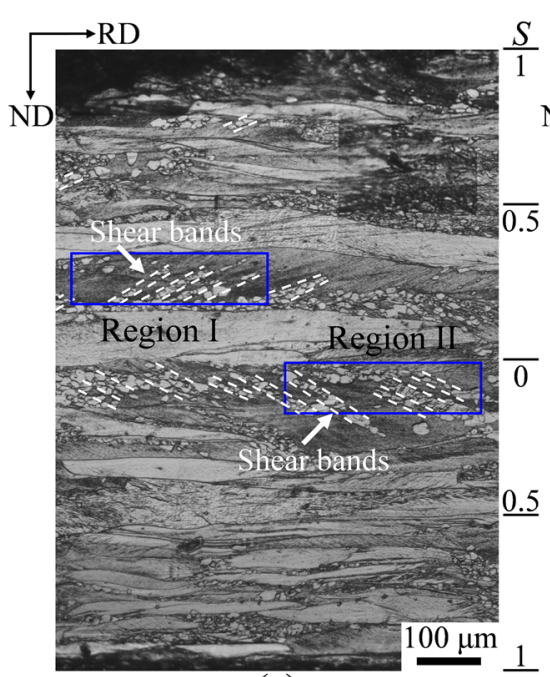

(a)

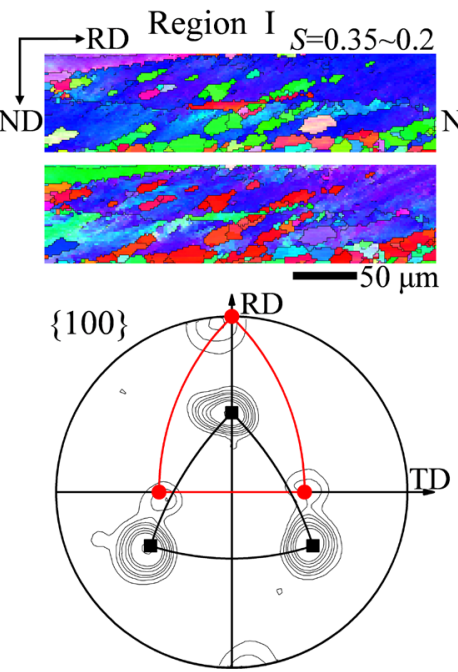

(b) $\{445\}<558>$

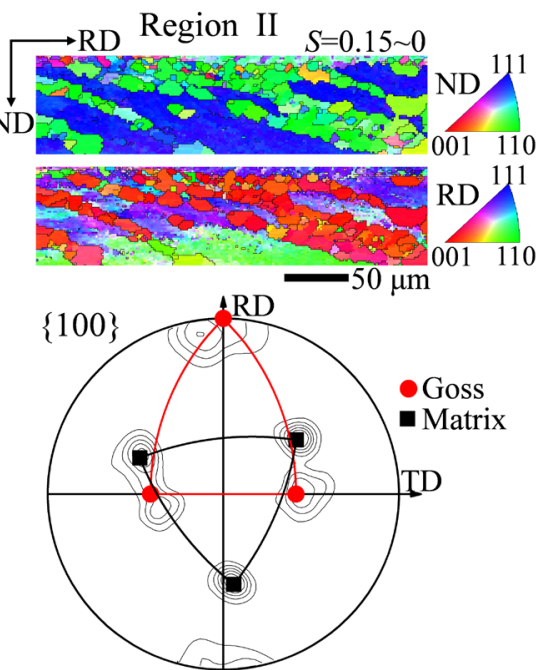

(c) $\{111\}<235>$

Figure 6. (a) Microstructure and (b, c) local enlarged orientation image maps marked in Figure 6(a) and corresponding $\{100\}$ pole figures of recrystallized grains and correspondingly surrounded deformed matrices for Goss nucleation sites in $10 \%$ recrystallized Fe- 2.1 wt. $\%$ Si sheets.

\section{Conclusions}

1. The most remarkable microstructure feature of cold rolled samples in current work is the formation of abundant shear bands, irrespective of the value of $S$. The formation of these shear bands benefits from the slightly heterogeneous microstructure with reduced grain size as $S$ value increases and optimized texture with weakened $\alpha$ texture at the $S=0$ layer.

2. Goss grains mainly nucleate at the shear bands in the deformed matrices which have special orientations spreading from $<112>/ / \mathrm{ND}$ to $<332>/ / \mathrm{ND}$ fibers. These orientations are distributed on both sides of $\gamma$ fiber and have a deviation angle about $0 \sim 20^{\circ}$ away from the accurate $\gamma$ fiber.

3. The improved recrystallization texture characterized with dominant Goss component through the thickness and significantly weak $\gamma$ fiber can be attributed to the suppression of the nucleation at grain boundaries of $\gamma$ deformed matrices and the promotion of the nucleation at shear bands in the deformed matrices with orientations spreading from $<112>/$ ND to $<332>/$ ND fibers.

\section{Acknowledgments}

This work was supported by the National Key Research and Development Program of China (No. 2016YFB0300305); National Natural Science Foundation of China (No. 51671049); Fundamental Research Funds for the Central Universities (No. N170213019); and China Scholarship Council (CSC) (No. 201806085006).

\section{References}

1. da Cunha MA, Paolinelli SC. Effect of the Annealing Temperature on the Structure and Magnetic Properties of $2 \%$ Si Steel. Materials Research. 2002;5(3):373-378

2. Park JT, Szpunar JA. Effect of initial grain size on texture evolution and magnetic properties in nonoriented electrical steels. Journal of Magnetism and Magnetic Materials. 2009;321(13):19281932.

3. Lee KM, Huh MY, Lee HJ, Park JT, Kim JS, Shin EJ, et al. Effect of hot band grain size on development of textures and magnetic properties in $2.0 \%$ Si non-oriented electrical steel sheet. Journal of Magnetism and Magnetic Materials. 2015;396:53-64.

4. Paolinelli SC, da Cunha MA, Cota AB. Effect of hot band grain size on the texture evolution of $2 \% \mathrm{Si}$ non-oriented steel during final annealing. IEEE Transactions on Magnetics. 2015;51(6):6200904.

5. Eloot K, Okuda K, Sakata K, Obara T. Texture Evolution during Cold Rolling and Recrystallisation of IF Steel with a Strong \{111\} Hot Band Texture. ISIJ International. 1998;38(6):602609.

6. Inagaki H. Nucleation of a $\{111\}$ Recrystallized Grain at the Grain Boundary of Cold Rolled Polycrystalline Iron. Transactions of the Japan Institute of Metals. 1987;28(4):251-263.

7. Barnett MR, Kestens L. Formation of $\{111\}<110>$ and $\{111\}<112>$ Textures in Cold Rolled and Annealed IF Sheet Steel. ISIJ International. 1999;39(9):923-929.

8. Park JT, Szpunar JA. Evolution of recrystallization texture in nonoriented electrical steels. Acta Materialia. 2003;51(11):30373051 .

9. da Cunha MA, Paolinelli SC. Low core loss non-oriented silicon steels. Journal of Magnetism and Magnetic Materials. 2008;320(20):2485-2489. 
10. Yao YC, Sha YH, Liu JL, Zhang F, Zuo L. Effect of Texture and Microstructure for Magnetic Properties of Two-Stage Cold-Rolled Fe-6.5 Wt Pct Si Thin Sheets. Metallurgical and Materials Transactions A. 2016;47(12):5771-5776.

11. Paolinelli SC, da Cunha MA, Cota AB. The influence of shear bands on final structure and magnetic properties of $3 \% \mathrm{Si}$ non-oriented silicon steel. Journal of Magnetism and Magnetic Materials. 2008;320(20):e641-e644.

12. de Campos MF, Landgraf FJG, Takanohashi R, Chagas FC, Falleiros IGS, Fronzaglia GC, et al. Effect of the Hot Band Grain Size and Intermediate Annealing on the Deformation and Recrystallization Textures in Low Silicon Electrical Steels. ISIJ International. 2004;44(3):591-597.

13. Cardoso RFA, Brandao L, da Cunha MA. Influence of grain size and additions of $\mathrm{Al}$ and $\mathrm{Mn}$ on the magnetic properties of non-oriented electrical steels with 3 wt. (\%) Si. Materials Research. 2008;11(1):51-55.

14. Grégori F, Murakami K, Bacroix B. The influence of microstructural features of individual grains on texture formation by straininduced boundary migration in non-oriented electrical steels. Journal of Materials Science. 2014;49(4):1764-1775.

15. Dorner D, Zaefferer S. Microstructure and Texture of Shear Bands in Cold Rolled Silicon Steel Single Crystals of Goss Orientation. Solid State Phenomena. 2005;105:239-244.

16. Murakami K, Morishige N, Ushioda K. The Effect of Cold Rolling Reduction on Shear Band and Texture Formation in Fe-3\%Si Alloy. Materials Science Forum. 2012;715-716:158163.

17. Haratani T, Hutchinson WB, Dillamore IL, Bate P. Contribution of shear banding to origin of Goss texture in silicon iron. Metal Science. 1984;18(2):57-66.
18. Samajdar I, Cicale S, Verlinden B, Van Houtte P, Abbruzzesse G. Primary recrystallization in a grain oriented silicon steel: on the origin of Goss $\{110\}<001>$ grains. Scripta Materialia. 1998;39(8):1083-1088.

19. Mishra S, Därmann C, Lücke K. On the development of the Goss texture in iron-3\% silicon. Acta Metallurgica. 1984;32(12):21852201.

20. Matsuo M, Sakai T, Suga Y. Origin and development of through-the-thickness variations of texture in the processing of grain-oriented silicon steel. Metallurgical Transactions A. 1986;17(8):1313-1322.

21. Shimizu Y, Ito Y, Iida Y. Formation of the Goss orientation near the surface of 3 pct silicon steel during hot rolling. Metallurgical Transactions A. 1986;17(8):1323-1334.

22. Shan N, Sha YH, Zhang F, Liu JL, Zuo L. Recrystallization Texture Transition in Fe-2.1 Wt Pct Si Steel by Different Cold Rolling Reduction. Metallurgical and Materials Transactions A. 2016;47(12):5777-5782.

23. Beausir B, Fundenberger JJ; ATEX. Analysis Tools for Electron and X-ray diffractions. Metz: Université de Lorraine; 2017. Available from: $<$ http://atex-software.eu $>$.

24. Park JT, Szpunar JA. Texture Development during Grain Growth in Nonoriented Electrical Steels. ISIJ International. 2005;45(5):743-749.

25. Dillamore IL, Roberts JG, Bush AC. Occurrence of shear bands in heavily rolled cubic metals. Metal Science. 1979;13(2):73-77.

26. Inagaki H. Fundamental Aspect of Texture Formation in Low Carbon Steel. ISIJ International. 1994;34(4):313-321. 